\title{
"Hey, I Can Do This!" The Benefits of Conducting Undergraduate Psychology Research for Young Adult Development
}

\author{
H. Russell Searight, PhD \\ Associate Professor, Department of Psychology \\ Lake Superior State University \\ Susan Ratwik, PhD \\ Professor, Department of Psychology \\ Lake Superior State University \\ Todd Smith, PhD \\ Assistant Professor, \\ St. Catharine College
}

Many undergraduate programs require students to complete an independent research project in their major field prior to graduation. These projects are typically described as opportunities for integration of coursework and a direct application of the methods of inquiry specific to a particular discipline. Evaluations of curricular projects have usually found that they positively impact students' knowledge and skills in that discipline. However, little attention has been devoted to the impact that these projects have on broader aspects of psychosocial development. The current study describes the results of a focus group conducted with students who had recently completed their senior research project in psychology. Results of the focus group interview were transcribed and coded according to grounded theory principles. Five developmentally-specific categories emerged from the analysis.

These included a greater sense of competence attributed to completing a large-scale project, an experience of being in a professional role relative to research

participants as well as to the audience presented with their study results, and a sense of ownership and pride in completing their project. Universities that either require or are contemplating requiring senior projects should consider these broader benefits to young adult development.

A decade ago, the Boyer Commission Report emphasized the role of research-based learning for undergraduate education-a theme echoed by the National Science Foundation (Boyer Commission on the Education of Undergraduates in the Research University, 1998; National Science Foundation, 2003). Since that time, multiple models of undergraduate research have been described, ranging from assistance with faculty research to completely independent student-driven inquiry.

Based upon longitudinal observation of college students followed until age 30 , Baxter-Magoda (2001) described a four-stage process of epistemological reflection that is helpful for appreciating the developmental impact of the undergraduate research experience. In this model, students move from a view of knowledge as the province of "experts" to one in which they come to appreciate that academic "truth" may, at times, be relative. This recognition is followed by an appreciation that most information is subject to revision through self-directed critical analysis. Finally, adults recognize the role of context when evaluating new knowledge, a stage that few young adults achieve by college graduation (Baxter-Magoda, 2001; Hunter, Laursen, \& Seymour, 2006).

By participating in the generation of new knowledge, supervised research socializes students into their discipline (Hunter, Laursen, \& Seymour, 2006). Ideally, 
the mentor is skilled in balancing the degree of didactic instruction (usually required early in the student's research career) with learner-centered initiative and responsibility. Additionally, the mentor recognizes that for emerging adults, conducting an independent research project is likely to impact identity and cognitive development, while for older non-traditional students there may be greater impact on socialization as a pre-professional into a "community of practice" (Holley \& Taylor, 2009; Wenger, 1998).

While some type of undergraduate research activity occurs in many psychology departments, curricular models vary considerably by institution. The recently published quality benchmarks guidelines for undergraduate psychology education provide a competency-based framework for research and scholarship (Dunn, McCarthy, Baker, Halonen, \& Hill, 2007). In teaching and supervising research, relevant competencies include applying knowledge from previous coursework such as research design, statistics and psychometrics, generating operational definitions of theoretical constructs from subfields within psychology (e.g., perception, cognition, learning, and personality), as well as ethical issues surrounding protection of human participants. These curricular components are also helpful in developing measurable outcomes increasingly required by bodies accrediting undergraduate programs.

Along with retention and graduation data, the success with which a student is able to apply didactic knowledge provides another method by which to assess a program's effectiveness. For example, in our program, students develop a research portfolio consisting of a log of research activity throughout their senior year, the Institutional Review Board application for conducting the project, a literature review, the final report of the project, and an accompanying poster. Products of this type complement traditional quantitative outcomes with rich descriptions of educational outcomes. Figure 1 outlines the specific components of Lake Superior State University's psychology

Along with retention and graduation data, the success with which a student is able to apply didactic knowledge provides another method by which to assess a program's effectiveness. research experience. Our program's belief in the importance of personal development and the value of the senior project extends back over 40 years to the beginning of the LSSU's undergraduate psychology program and the university's establishment as four-year institution. The importance of personal development in psychology majors at LSSU was previously addressed in 1993, in the psychology program's self-study (Gibson, Malmberg, Ratwik, Sawyer, Trouvé, \& Voight, 1993). At that time, the psychology program adopted the undergraduate psychology goals established by McGovern, Furomoto, Halpern, Kimble, and McKeachie (1991), including interpersonal skills (expanded selfknowledge, the ability to monitor one's own behavior, sensitivity to individual differences, and an ability to work effectively in groups), and suggested that these skills could "complement the cognitive achievements of the traditional course of study in psychology" (McGovern et al., p. 602). The LSSU psychology program proposed that the "psychology [program] promotes student efficacy through success in demanding course activities, personal self study, and learning experiences designed to challenge student assumptions" (p. 23). The program's focus on personal development was consistent with the University's Mission Statement at that time, which included "providing opportunities for emotional and social maturation as well as intellectual growth, with a commitment to fostering the development of students as "fulfilled, caring individuals" (Gibson et al.., 1993).

The 1993 self-study broadly assessed the personal development of psychology majors and to some extent evaluated the effect of the senior research experience on personal development with a variety of assessment approaches. In a 
survey sent to alumni from 1969-1992, with a response rate of $25 \%(\mathrm{~N}=58)$, students cited the senior research experience as one of their most memorable experiences. In addition, $88 \%$ reported that the psychology program helped them with interpersonal skills, $87 \%$ described tolerance for others as improved, and $90 \%$ "gained a success/achievement-oriented perspective toward life in general" ( p. 44).

Most previous investigations of undergraduate research have focused on pedagogical issues and discipline-specific knowledge and skills (Seymour, Hunter, Laursen, \& DeAntonini, 2004). While limited, some attention has been given to broader cognitive-developmental goals such as demonstrating self-regulation in setting and achieving goals as well as metacogntive skills such as evaluating the quality of one's own reasoning (Baxter Magolda, 2004). However, these personal and professional developmental

The current investigation highlights the impact of conducting research for the students' personal, epistemological, and professional development.

objectives still are primarily cognitive in nature. While there are suggestions that students completing undergraduate research projects may value personal developmental outcomes over cognitive skills (Hunter, Laursen, \& Seymour, 2006), these psychosocial outcomes have received relatively little attention.

The current investigation highlights the impact of conducting research for the students' personal, epistemological, and professional development. Since the impact of conducting research on these dimensions has not been well-studied and because the topic focused on subjective experiences, qualitative methods were employed (Searight \& Young, 1994). Specifically, a focus group was conducted with participants who had recently completed their senior psychology research projects.

\section{Methods}

\section{Participants}

A focus group was conducted that was comprised of 15 students ( 4 males and 11 females) who had recently completed their psychology senior research project. The modal age was approximately 22 years old, with one student in his late twenties and another in his early forties. The group was facilitated by the first author who had not been involved with supervising any of the students. The session was tape-recorded and later transcribed. Before signing a consent form, participants were assured of confidentiality and it was explained that while direct quotations would be part of the written report; no one would be identified, either by name or by other characteristics.

\section{Interview}

Qualitative studies of this type typically employ an interview method that begins with broad, open-ended queries. The interviewer, as noted above, did not supervise any of the projects. As is often recommended by qualitative research methodologists (Glaser \& Strauss, 1967; Strauss \& Corbin, 1990), previously published studies on the topic were not read prior to conducting the group. This restriction is designed to prevent the investigator from being influenced by preexisting information in the area.

While there were some general guidelines for interview topics, the session began with open-ended questions (e.g., "Tell me about your experience with senior research?") (McCracken, 1988). These "grand tour" questions are followed up with specific probes or "mini tour" queries (e.g., "Running subjects sounds important. Could you say more about that? ") to clarify categories and their respective 
boundaries. Later queries also include contrast questions (e.g., "How did this experience compare with other large academic projects that you have done?") (McCracken, 1988; Spradley, 1979).

\section{Data Analysis}

Data was in the form of interview transcripts. Grounded theory principles were used as a framework to analyze the data and organize the information around themes that inductively emerge (Strauss \& Corbin, 1990). Through this coding process, between five and eight themes or categories typically emerge.

The overall goal of this type of analysis is to obtain a description of participants' subjective experience and meaning regarding the topic of study (Hammersley \& Atkinson, 1983). Results are typically presented in the form of descriptive themes. Direct quotations from the interview narratives are frequently employed to illustrate the themes.

\section{Results}

As noted above, some students shared significant feedback regarding the content of the program. Much of this was idiosyncratic to the institution and the department. Because it was believed to be more meaningful and generalizable to other institutions, this analysis will focus primarily on categories centering on broader developmental themes. Each domain is labeled and has an accompanying story line. A description of that domain or theme is followed by (a) representative quotation(s) to illustrate the domain.

Domain One: The Experience of Completing a Large-scale Independent Project ("You gotta make it work")

Nearly all the students indicated that they had never taken on or completed a long-range project of this type. As they had recently completed their research, the students were able to look back to the product with some sense of achievement. This exchange, between an older student and several participants of "traditional "college age, illustrates this experience:

$S$ (1): "...if you never held a real job or did anything like a big task. For a lot of people it could be the first time they did. I think that alone is worth it, "S (2) "you have to be responsible..." S (3): "You schedule time..." S (4): "You gotta make it work."

$S$ (1)..." don't get discouraged, like halfway through, you get so frustrated."

Domain Two: Appreciating the Research Process ("...you have to respect the process because man, this is work !")

The ability to see firsthand how the research that they had been reading for most of their college career was actually conducted yielded unique insights. They gained a much deeper, experiential appreciation of how empirical psychological knowledge is generated. Conducting research was a valuable complement to classes and reading.

S (5): "I think that it's worthwhile....just so you can see how it all comes together...you read some crap article, what was that guy's problem? ... and you're still like that's a lot of work!"

S (6): "Yeah, well he did the experiment..." S (5): Even though it didn't come out, he spent a lot of time on it...you kind of have to respect the whole process." 
Domain Three: Interpersonal Confidence and Competence ("I learned how to talk to people- like some professor you never met.")

A number of students reported that being placed in a professional role requiring them to interact with peers, faculty from other universities, and their own study participants, was extremely valuable. Several of the focus group members indicated that this was the first time that they had felt like they were in a role of this type. Many students indicated that presenting their findings at an undergraduate research conference was a unique, confidence-building experience:

S(8): "...just meeting with subjects, interacting with a lot of people \{at the research conference\} I did what I had to do but then...all right, I should mingle around..." S (3) "...and talk to some professor you never met!" [Laughter]

There was a strong consensus that directly obtaining their data from their own participants was very important and a key benefit from conducting the project. Participants were nearly unanimous in indicating that they were not particularly interested in conducting analyses of archival data. This excerpt is from an exchange about students' reaction to using archival data:

$S$ (7): "I personally like running subjects... S (8): Yeah...S (9): "I think if we just took the data we wouldn't get as good an experience...like the full experience."

Domain Four: The Importance of Independence ("I think it's important to start from...it's your idea. It should be your project-always")

Participants repeatedly stressed their individual ownership of their project. By owning the project, participants found a sense of freedom and scholarly independence that was new to their college experience. This ownership and accompanying responsibility for the project could also be anxiety-provoking:

$S(10)$ : "It's finally something unique to the person because you can pick any topic, anything that interests you....like a lot of the psych courses, its all laid out for you, this is want you gotta do, this is the reading you do...boom, boom, boom...then you get here, ok, what do you want to do..." $S(10)$ : "Yeah, you actually get that freedom because it's more in your area of interest...that was one of the most enjoyable things about it...that's kind of cool rather than 'yawn'; it's definitely good to have this freedom."

Through their participation in the undergraduate research conference, students encountered different models of research-frequently, they interacted with faculty-led student teams focusing on that faculty member's research. The participants did not see this common practice of working in teams on faculty research to be particularly attractive. It was seen as eliminating the freedom to pursue their own unique interests and as leading to a product that they would view with little personal investment.

S (11): "One thing I did when I went to this conference...I was glad I did it independently...there were people [other student-presenters]...who did it as fours, twos and threes...if I had been in a group, you just rely on others' strengths.....S (3)...and you had more freedom doing it independently, you didn't have to agree on something." 
Domain Five: Leaving and Owning a Legacy ("None of our stuff is copyrighted so people can technically use it without our permission. That sucks!")

Students were possessive of their completed projects. A common concern was that their data would be given to successive years of senior students for their own projects. This possibility was greeted with resentment that next year's seniors would not have to work as hard nor as independently as the current group members:

$S$ (11): "I got a question...[the psychology department] is getting all our CDs. Five years down the road ...somebody wants to use [my] project...I'm the one who really started it...I have the program !" S (13): "That's another thing. Are they gonna let people use our material? S (4): I think they should have to e-mail us..."

This exchange escalated with increased concern that the product of the current students' research would be given away freely to students who followed:

$S$ (12):" Yeah, they should e-mail and I should charge them...because there's no way...I put in eight days in the lab. S (14): "...our hard work they're taking advantage of...S (11): "Yeah!" "I don't think that's right ...give me that digital file back ! [laughs]." S (14):"...Oh great, here's my project. Sweet, you know!" S (3): "Our hard work they're taking advantage of..."S (10): "Yeah, I don't think that's right"

\section{Discussion}

Senior research, while challenging, appears to be an important developmental milestone for emerging adult students. In addition to formal academic skills such as data analysis, writing a proposal, and presenting results, students viewed the project as particularly valuable for building a sense of competence and for helping them feel that they were "professionals" $-a$ role that they will likely fill after leaving the undergraduate institution.

The majority $(87 \%)$ of our students were young adults in their early twenties. It is likely that for the small number of older, non-traditional students, the benefits were somewhat different. Anecdotally, there were suggestions that these non-traditional students were less concerned about self-confidence and identity-related issues. With these issues addressed, they were better able to appreciate the context in which

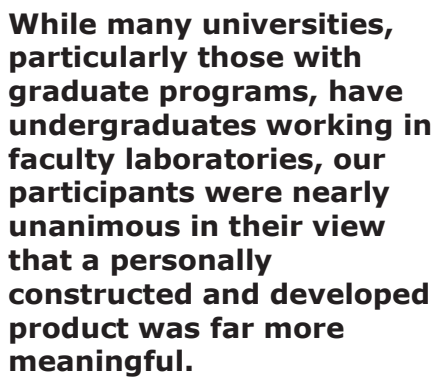
psychological knowledge is generated-a stage that Baxter-Magoda (2001) suggests is not attained until the post-college years.

The original intent of the current investigation was to obtain feedback on the research component of our undergraduate curriculum and was not specifically focused on developmental issues. It is likely that a richer description of students' undergraduate research experiences would be obtained with interviews specifically focused on psychosocial aspects guided by a developmental theory.

While many universities, particularly those with graduate programs, have undergraduates working in faculty laboratories, our participants were nearly unanimous in their view that a personally constructed and developed product was far more meaningful. Participants cited the personal investment that they had in a project that they had developed from the beginning and that reflected their own unique and distinctive interests. There was a very strong theme of the importance 
of personal ownership of the research project. A number of participants, including the one whose comment served as the title for this paper, seemed both surprised and pleased that they could complete a project of this magnitude with a reasonable degree of independence.

The ability to carry out a multi-step project, conducted over the course of an academic year, is a transferable skill valued by potential employers. The acquisition of project management skills is of particular importance, since many of our participants indicated that they did not, at least at present, plan on entering graduate school in psychology.

Students were very protective of their finished products. While faculty do not give the seniors' data to upcoming students and treat these completed projects according to accepted principles of research ethics, the participants expressed pronounced concern that junior students would take their data and/or redo a project that they viewed as a hard-won personal accomplishment.

Many undergraduate programs make an independent capstone project optional for graduation, while other institutions have undergraduate students assisting with faculty or graduate student projects. While this latter experience has value and may be particularly useful for helping students see skilled investigators at work, as well as to have a publication as part of their graduate school application, this option appeared to be significantly less attractive to the students interviewed in this study. Additionally, while undergraduate students conducting their own research are frequently confined to gathering data on fellow college undergraduates, running one's own subjects was described as more valuable than analyzing an archival data set.

Finally, students indicated that they had a much deeper appreciation of the amount of work that goes into completing a psychological study. Even those studies that they had often criticized in their course work were viewed with newfound appreciation, expressed in remarks like "You have to respect the process."

\section{References}

Baxter Magoda, M.B. (2001). Making their own way: Narratives for transforming higher education to promote self-development. Sterling, VA: Stylus.

Baxter Magolda, M. B. (2004). Evolution of a constructivist conceptualization of epistemological reflection. Educational Psychologist, 39, 31-42.

Boyer Commission on Educating Undergraduates in the Research University (2002). Reinventing undergraduate education: Three years after the Boyer Report. Stony Brook, NY: State University of New York at Stony Brook.
Dunn, M.A., McCarthy, S., Baker, S., Halonen, J.S., \& Hill, J.J. (2007).

Quality benchmarks in undergraduate psychology programs. American Psychologist, 62, 650-670.

Gibson, Malmberg, M., Ratwik, S., Sawyer, T., Trouve, R., \& Voight, (1993). Lake Superior State University Department of Psychology Self-Study. Unpublished manuscript.

Glaser, B. G., \& Strauss, A. (1967). The discovery of grounded theory: Strategies for qualitative research. Chicago: Aldine Publishing Co.

Hammersley, M., \& Atkinson, P. (1983). Ethnography: Principles in practice. New York: Tavistock Publications. 
Holley, K. A. \& Taylor, B. J. (2009). Undergraduate socialization and learning in an online professional curriculum. I nnovative Higher Education, 33, 257-269.

Hunter, A. B., Laursen, S. L. \& Seymour, E. (2006). Becoming a scientist: The role of undergraduate research in students' cognitive, personal, and professional development. Science Education, 91, 36-74.

McCracken, G. D. (1988). The long interview. Newbury Park, CA: Sage.

McGovern, T.V., Furmoto, L., Halpern, D.F., Kimble, G.A., \& McKeachie, W.J. (1991). Liberal education, study in depth, and the arts and science major-psychology. American Psychologist, 46, 598-605.

National Science Foundation (2003). Enhancing research in the chemical sciences at predominantly undergraduate institutions. Report from the Undergraduate Research Summit. Lewiston, ME: Bates College.
Searight, H. R., \& Young, R. (1994). Qualitative research and family systems medicine: A natural fit. Family Systems Medicine, 12, 117131.

Seymour, E., Hunter, A. B., Laursen, S. J., \& DeAntoni, T. (2004).

Establishing the benefits of research experiences for undergraduates in the sciences: First findings from a three year study. Science Education, $88,493-534$.

Spradley, J. P. (1979). The ethnographic interview. New York; Harcourt Brace.

Strauss, A. \& Corbin, J. (1990). Basics of qualitative research. Newbury Park, CA: Sage.

Wenger, E. (1998). Communities of practice: Learning, meaning, and identity. Cambridge, MA: Cambridge University Press.

\section{Figure 1: Overview of Year-Long Psychology Senior Research Experience at}

Lake Superior State University

\section{Semester I}

Review of Experimental and QuasiExperimental Design Critical Analysis of Published Research

Review of Statistical Methods Data Analysis Procedures: Statistical Package for the Social Sciences (SPSS)

Literature Search Strategies Developing Testable Hypotheses Operationalizing Constructs: Psychometric Issues Research Ethics and the Role of the Institutional Review Board Format for Presenting Research Findings (Mock Poster and Tables) Plan for Data Collection

\author{
Semester II \\ Completion of I nstitutional Review \\ Board Proposal \\ If Necessary, Modification of Project \\ Based on IRB Feedback \\ Pilot Testing of Study Procedures on \\ Fellow Students and Faculty \\ Recruiting Study Participants \\ Data Gathering \\ Data Analysis \\ Write Research Report \\ Construct Poster \\ Present Poster at State-Wide \\ Undergraduate Psychology Research \\ Conference \\ Present Poster at LSSU Poster \\ Session for General University \\ Audience
}


H. Russell Searight received his PhD in clinical psychology from St. Louis University in 1984. He received a Masters in public health from St. Louis University School of Public Health in 2003. He is currently Associate Professor of Psychology at Lake Superior State University in Sault Sainte Marie, Michigan. He has previously held faculty positions at Southern Illinois University -- Edwardsville, St. Louis University, and St. Louis University School of Medicine. In addition to the psychosocial development of emerging adult college students, his scholarly interests include the practice of psychology in primary health care and medical ethics.

Susan H. Ratwik received her BA in Psychology from the University of Minnesota. She received her PhD in Psychology from the University of Notre Dame in 1978. For a number of years, Dr Ratwik served as the Chairperson of Lake Superior State University's Psychology Department. In 1990, she received the University's Distinguished Teacher Award. She teaches courses in research, statistics, experimental psychology, child development, and social psychology. Dr Ratwik has also supervised the senior research projects described in this article for over 20 years. Her research and scholarly interests include language development among persons with Down Syndrome.

Todd J. Smith received his BA in both psychology and biochemistry from Maryville College. He received his $P h D$ in experimental psychology from the University of Tennessee. Dr. Smith is currently Assistant Professor and Director of the Psychology program at St. Catharine College in St. Catharine, Kentucky. He has held previous faculty positions at Lake Superior State University, Pikeville College, and the University of Maryland College in Europe. His area of research is in animal behavior - specifically the behavior of zoo animals. 